\title{
The Johansson-Samuelson Theorem in General Equilibrium: A Rebuttal
}

\author{
FRANCESCO MENONCIN \\ PAOLO M. PANTEGHINI
}

CESIFO WORKING PAPER NO. 2352

CATEgory 1: PubliC FinAnCE

JULY 2008

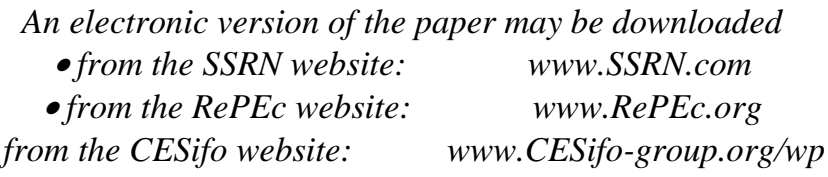




\title{
The Johansson-Samuelson Theorem in General Equilibrium: A Rebuttal
}

\begin{abstract}
The well-known Johansson-Samuelson Theorem proves that, in partial equilibrium, comprehensive income taxation with a uniform tax rate is neutral in terms of investment decisions, if fiscal depreciation allowances coincide with economic depreciation. In this article we show that this result does not hold in general equilibrium, unless fairly restrictive conditions are met.
\end{abstract}

JEL Code: H25, H32.

Keywords: general equilibrium, investment neutrality, uniform taxation.

Francesco Menoncin

University of Brescia

Department of Economics

Via S. Faustino 74/B

25122 Brescia

Italy

menoncin@eco.unibs.it
Paolo M. Panteghini

University of Brescia

Department of Economics

Via S. Faustino 74/B

25122 Brescia

Italy

panteghi@eco.unibs.it

The authors would like to thank Alan J. Auerbach, Rainer Niemann and Peter Birch Sørensen for their helpful comments on a draft containing the main ideas of this article. The authors are responsible for any errors. 


\section{Introduction}

Uniform comprehensive income taxation is a popular policy option. ${ }^{1}$ Advocates of this tax argue not only that it is fair, but also that it is neutral in terms of investment decisions. According to the well-known JohanssonSamuelson Theorem (JST), ${ }^{2}$ if all kinds of capital are subject to the same marginal tax rate and fiscal depreciation allowances coincide with economic depreciation, then investment strategies are unaffected by taxation.

It is worth noting that the JST has been proven in a partial-equilibrium model. In this article we therefore aim to analyze the JST in general equilibrium. To do so we refer to two streams of literature. The first one deals with the JST and provides some generalizations of its basic results in partial equilibrium. In particular, Fane (1987) and Richter (1988) prove that this theorem holds even if the investment return and the resale value of capital are stochastic. Moreover, Niemann (1999) shows that the JST holds in a real-option setting. ${ }^{3}$ In a subsequent article, Niemann (2004) also proves that neutrality is ensured even under tax rate uncertainty. ${ }^{4}$

The second stream of literature deals with the effects of taxation in general equilibrium. Starting from the pioneering article by Domar and Musgrave (1944), ${ }^{5}$ Kaplow (1994) has improved this topic by dealing with a government's ability to influence risk taking through portfolio investments as well as through tax policy. He has shown that in this context, many partial equilibrium results fail to hold. Quite recently, Abel (2007) has analyzed both consumption-based and comprehensive income taxation in a deterministic general equilibrium model. He has shown that, while consumption-based

\footnotetext{
${ }^{1}$ Its popularity is, e.g., shown by the US Report of the President's Advisory Panel on Tax Reform (2005).

${ }^{2}$ The JST is the joint result of Johansson's $(1961,1969)$ and Samuelson's (1964) findings. For a discussion of the JST see, e.g., Sinn (1987, ch. 5) and Lyon (1990).

${ }^{3}$ For a discussion on tax neutrality in a real-option setting see, e.g., Panteghini (2007).

${ }^{4}$ Another interesting result is that found by Hartwick et al. (2002), who identify a depreciation rule that does not encourage extractive firms to deviate from a laissez-faire strategy.

${ }^{5}$ See also Bulow and Summers (1984) and Gordon (1985), who have analyzed the effects of taxation on risk taking. In particular, Bulow and Summers (1984) have pointed out that the asset price volatility can lead to a huge impact in terms of both revenue raising as well as to distortions. On the other hand, Gordon (1985) has proven that, under certain conditions, taxation has negligible impact on the equilibrium allocation and at the same time, allows the collection of a large amount of revenue. For further details on this topic see Devereux (2003).
} 
taxation is a neutral and powerful revenue-raiser, comprehensive taxation has many shortcomings. In particular, he has shown that under a comprehensive income tax, it is possible to find a neutral fiscal depreciation allowance (in line with that proposed by Hall and Jorgenson, 1971, and Boadway and Bruce, 1984), although de facto this rule leads to the collection of no revenue. ${ }^{6}$

In this article, we will merge these two streams of literature, and study the JST in general equilibrium. We will show that the JST is violated, in that its depreciation rule does not ensure tax invariance of both a firm's value and market prices, unless quite restrictive conditions are met. Moreover, we will also see that the neutral depreciation rule in general equilibrium suffers from implementation problems.

The structure of the article is as follows. Section 2 introduces income and interest rate risk and discusses the JST in partial equilibrium. Section 3 introduces a stochastic general equilibrium model and compares our findings with those obtained in partial equilibrium. Section 4 summarizes our results and discusses their policy implications.

\section{The JST in a stochastic context}

In order to understand the JST in a general equilibrium setting, we first need to see under which conditions the JST holds in partial equilibrium. Let us therefore focus on a representative firm, that faces both income and interest rate risk. Accordingly, let us introduce the following:

Assumption 1 From time $t_{0}$ to time $T$, a representative firm receives a cash flow $\pi(t)$ that evolves according to the following stochastic process:

$$
d \pi(t)=\mu_{\pi}(t, \pi) d t+\sigma_{\pi \times k}^{\prime}(t, \pi) \underset{k \times 1}{W}(t)^{\mathbb{Q}}, \quad \pi\left(t_{0}\right)=\pi_{0}
$$

where $\mu_{\pi}(t, \pi)$ is the instantaneous expected growth, $\sigma_{\pi}(t, \pi) \in \mathbb{R}^{k}$ is the instantaneous standard deviation of growth, $d W^{\mathbb{Q}}(t)$ is a vector of independent Wiener processes, under the risk-neutral probability measure $\mathbb{Q}$, and the prime denotes transposition.

\footnotetext{
${ }^{6}$ Notice however that Abel's (2007) zero-tax-revenue result crucially depends on the technology introduced. In fact, he assumes that a firm's production function is linearly homogeneous in capital and labor.
} 
Assumption 2 The spot interest rate evolves as follows:

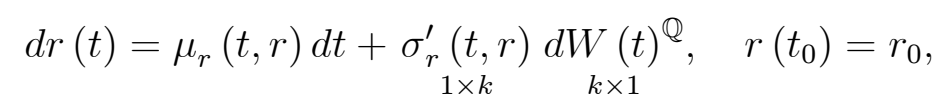

where $\mu_{r}(t, r)$ is the instantaneous expected growth, and $\sigma_{r}(t, \pi) \in \mathbb{R}^{k}$ is the instantaneous standard deviation of growth.

Assumptions 1 and 2 allow us to deal with both non-systematic and systematic risk. The former is related to the firm-specific stochastic process (1) and is embedded in the diffusion term $\sigma_{\pi}(t, \pi)$. The latter is due to the volatility of the financial system, and is therefore embedded in the diffusion term $\sigma_{r}(t, r)$ of process (2). The instantaneous correlation between $\pi(t)$ and $r(t)$ is given by

$$
\sigma_{\pi}^{\prime}(t, \pi) \sigma_{r}(t, r) d t
$$

When cash flow and interest rate are not correlated, cash flow risk cannot be completely diversified and therefore, process (1) also affects systematic risk. We have no a priori on the sign of correlation. ${ }^{7}$ For simplicity, hereafter we will omit all the functional dependences for drift and diffusion terms.

Let us next denote $\delta(s)$ and $\tau$ as the fiscal depreciation allowance at time $s$ and the uniform tax rate levied on a firm's income, respectively. Under the assumption that the relevant tax system is fully symmetric, a firm's after-tax cash flow at time $s$ is thus equal to $[(1-\tau) \pi(s)+\tau \delta(s)]$. Therefore, a firm's expected present value at any time $t \in\left[t_{0}, T\right]$ is equal to

$$
V_{\tau}(t)=\int_{t}^{T} \mathbb{E}_{t}^{\mathbb{Q}}\left[((1-\tau) \pi(s)+\tau \delta(s)) e^{-\int_{t}^{s}(1-\tau) r(u) d u}\right] d s,
$$

where $\mathbb{E}_{t}^{\mathbb{Q}}[$.$] is the expectation operator, conditional on the information avail-$ able at time $t$, and under the risk neutral probability measure $\mathbb{Q} .^{8}$

\footnotetext{
${ }^{7}$ The correlation between cash flow and the interest rate is taken into account by Berk et al. (1999). In their numerical simulations they assume a negative covariance between a firm's cash flow and the spot interest rate. Their hypothesis fits well with the characteristics of manufacturing firms. Indeed, as long as a manufacturing firm is debtfinanced, an increase in the interest rate is expected to reduce cash flow and vice versa. On the other hand, banks are a remarkable example of positive correlation. In this case, an increase in the interest rate is expected to raise both their spread margin and cash flow.

${ }^{8}$ In an arbitrage-free market, the value of any traded asset is given by the expected present value of its future cash flows discounted with the risk-free interest rate, under the risk-neutral probability. For further details on the risk-neutral probability see, e.g., Björk (1998).
} 
A firm's value $V_{\tau}(t)$ can also be found as the solution of a partial differential equation. Applying the Feynman-Kač theorem (see Björk, 1998, pp. 59-60), the expected value $V_{\tau}(t)$ is the solution of the following partial differential equation:

$$
\begin{aligned}
& (1-\tau) r(t) V_{\tau}(t)-[(1-\tau) \pi(t)+\tau \delta(t)] \\
= & \frac{\partial V_{\tau}(t)}{\partial t}+\frac{\partial V_{\tau}(t)}{\partial \pi(t)} \mu_{\pi, \tau}+\frac{\partial V_{\tau}(t)}{\partial r(t)} \mu_{r, \tau}+\frac{1}{2} \frac{\partial^{2} V_{\tau}(t)}{\partial \pi(t)^{2}} \sigma_{\pi, \tau}^{\prime} \sigma_{\pi, \tau} \\
& +\frac{1}{2} \frac{\partial^{2} V_{\tau}(t)}{\partial r(t)^{2}} \sigma_{r, \tau}^{\prime} \sigma_{r, \tau}+\frac{\partial^{2} V_{\tau}(t)}{\partial r(t) \partial \pi(t)} \sigma_{\pi, \tau}^{\prime} \sigma_{r, \tau},
\end{aligned}
$$

where $\mu_{\pi, \tau}, \mu_{r, \tau}, \sigma_{\pi, \tau}$, and $\sigma_{r, \tau}$ are the after-tax drift and diffusion terms of cash flow and interest rate, and where both the RHS and the LHS must be equal to $\frac{1}{d t} \mathbb{E}_{t}^{\mathbb{Q}}\left[d V_{\tau}(t)\right] .^{9}$

Let us next introduce the zero-tax value function:

$$
V(t)=\mathbb{E}_{t}^{\mathbb{Q}}\left[\int_{t}^{T} \pi(s) e^{-\int_{t}^{s} r(u) d u} d s\right] .
$$

Again, applying the Feynman-Kač theorem, and differentiating (5) gives

$$
\begin{aligned}
r(t) V(t)-\pi(t)= & \frac{\partial V(t)}{\partial t}+\frac{\partial V(t)}{\partial \pi(t)} \mu_{\pi}+\frac{\partial V(t)}{\partial r(t)} \mu_{r}+\frac{1}{2} \frac{\partial^{2} V(t)}{\partial \pi(t)^{2}} \sigma_{\pi}^{\prime} \sigma_{\pi}(6) \\
& +\frac{1}{2} \frac{\partial^{2} V(t)}{\partial r(t)^{2}} \sigma_{r}^{\prime} \sigma_{r}+\frac{\partial^{2} V(t)}{\partial r(t) \partial \pi(t)} \sigma_{\pi}^{\prime} \sigma_{r},
\end{aligned}
$$

where both the RHS and the LHS must be equal to $\frac{1}{d t} \mathbb{E}_{t}^{\mathbb{Q}}[d V(t)]$.

Using (4) and (6) we can find a depreciation rule that ensures the equality $V(t)=V_{\tau}(t), \forall t$. Notice that the boundary conditions

$$
V(T)=V_{\tau}(T)=0
$$

${ }^{9}$ We can rewrite (4) as a well-known non-arbitrage condition:

$$
(1-\tau) r(t) V_{\tau}(t)=[(1-\tau) \pi(t)+\tau \delta(t)]+\frac{\mathbb{E}_{t}^{\mathbb{Q}}\left[d V_{\tau}(t)\right]}{d t},
$$

that entails the equality between the after-tax return on a default-free asset, on the LHS, and the firm's expected return, on the RHS. Terms $[(1-\tau) \pi(t)+\tau \delta(t)]$ and $\frac{\mathbb{E}_{t}^{\mathbb{Q}}\left[d V_{\tau}(t)\right]}{d t}$ measure a firm's after-tax cash flow and the expected change of value over the interval $d t$, respectively. 
hold. This means that, irrespective of taxation, a firm's value is nil at time $T$. Let us next equate the RHSs of Equations (4) and (6). We set $V(t)=V_{\tau}(t)$ for $t<T$, and solve for $\delta(t)$. We therefore obtain the neutral depreciation rule

$$
\begin{aligned}
\delta(t)= & r(t) V(t)-\pi(t) \\
& +\frac{\partial V(t)}{\partial \pi(t)} \frac{\mu_{\pi}-\mu_{\pi, \tau}}{\tau}+\frac{\partial V(t)}{\partial r(t)} \frac{\mu_{r}-\mu_{r, \tau}}{\tau} \\
& +\frac{1}{2} \frac{\partial^{2} V(t)}{\partial \pi(t)^{2}} \frac{\sigma_{\pi}^{\prime} \sigma_{\pi}-\sigma_{\pi, \tau}^{\prime} \sigma_{\pi, \tau}}{\tau}+\frac{1}{2} \frac{\partial^{2} V(t)}{\partial r(t)^{2}} \frac{\sigma_{r}^{\prime} \sigma_{r}-\sigma_{r, \tau}^{\prime} \sigma_{r, \tau}}{\tau} \\
& +\frac{\partial^{2} V(t)}{\partial r(t) \partial \pi(t)} \frac{\sigma_{\pi}^{\prime} \sigma_{r}-\sigma_{\pi, \tau}^{\prime} \sigma_{r, \tau}}{\tau}
\end{aligned}
$$

In other terms, we can say that neutrality holds if and only if the fiscal depreciation allowance satisfies (8).

It is worth noting that if the drift and diffusion terms are unaffected by taxation (i.e., $\mu_{\pi}=\mu_{\pi, \tau}, \mu_{r}=\mu_{r, \tau}, \sigma_{\pi}=\sigma_{\pi, \tau}$, and $\sigma_{r}=\sigma_{r, \tau}$ ), then (8) reduces to the well-known JST depreciation rule:

$$
\delta(t)=r(t) V(t)-\pi(t)=-\frac{1}{d t} \mathbb{E}_{t}^{\mathbb{Q}}[d V(t)] .
$$

The equalities $\mu_{\pi}=\mu_{\pi, \tau}, \mu_{r}=\mu_{r, \tau}, \sigma_{\pi}=\sigma_{\pi, \tau}$, and $\sigma_{r}=\sigma_{r, \tau}$ are not only sufficient but also necessary conditions. In fact, the five last terms of the RHS of Equation (8), containing the derivatives of $V(t)$ with respect to $\pi(t)$ and $r(t)$, are nil for any value of $\pi(t)$ and $r(t)$ only if $\mu_{\pi}=\mu_{\pi, \tau}, \mu_{r}=\mu_{r, \tau}$, $\sigma_{\pi}=\sigma_{\pi, \tau}$, and $\sigma_{r}=\sigma_{r, \tau}$. Therefore, we can conclude that:

Lemma 1 The JST depreciation rule (9) guarantees tax neutrality if and only if the drift and diffusion terms of state variables $(r(t)$ and $\pi(t))$ are unaffected by taxation.

The condition of Lemma 1 implicitly holds in partial equilibrium setting. As we will show however, in general equilibrium, the drift and diffusion terms of the state variables can be distorted by taxation. Therefore, the condition of Lemma 1 is not easily met. 


\section{A general equilibrium approach}

In section 2 we have shown that the depreciation rule of the JST is valid if, according to Lemma 1, the stochastic processes driving the state variables (cash flow and interest rate) are unaffected by taxation. In this section we show that such a condition may fail to hold in a general equilibrium framework where: (i) cash flows are the endowments of economic agents, and (ii) the interest rate is endogenously determined. In particular, we will find a depreciation rule that ensures tax invariance of market prices. However, this depreciation rule does not coincide with the JST depreciation rule (8), unless harsher conditions are met. ${ }^{10}$

The representative consumer On the economy there is a representative consumer who fully owns the only firm in the economy. Preferences on the intertemporal consumption $c(t)$ are described by a strictly increasing and concave utility function, represented by $e^{-\rho t} U(c(t))$, where $\rho$ is an exogenously given time preference rate. Moreover, we assume that the firm distributes all the after-tax cash flow to the consumer. Using the notation of section 2 we can therefore say that at any time $t$, the representative consumer receives the dividend $[(1-\tau) \pi(t)+\tau \delta(t)]$.

At time $t_{0}$, the consumer maximizes the expected utility of his intertemporal consumption from time $t_{0}$ to time $T$, under an intertemporal budget constraint. Since the discounted value of all his future consumption must be equal to the present value of his wealth, $R\left(t_{0}\right)$, the consumer's problem is as follows:

$$
\begin{gathered}
\max \mathbb{E}_{t_{0}}\left[\int_{t_{0}}^{T} e^{-\rho\left(t-t_{0}\right)} U(c(t)) d t\right] \\
\text { s.t. } R\left(t_{0}\right)=\mathbb{E}_{t_{0}}\left[\int_{t_{0}}^{T} c(t) \frac{B\left(t_{0}\right)}{B(t)} m\left(t_{0}, t\right) d t\right],
\end{gathered}
$$

where $m\left(t_{0}, t\right)$ is the kernel price (i.e., the stochastic discount factor), and $B(t)$ is the market value of a risk-free asset.

\footnotetext{
${ }^{10}$ This general equilibrium model mainly draws on Merton (1990), Gomes et al. (2003) and Vasiček (2005). Notice that the quality of results does not change if we assume more than one agent (see, e.g., Cvitanić and Zapatero, 2004).
} 
Capital market We assume that there are $n$ risky assets and one risk-free asset. In the absence of taxation, the financial market is therefore described by the following differential equations:

$$
\begin{aligned}
& \underset{n \times n}{I_{S}^{-1}} \underset{n \times 1}{S(t)}=\underset{n \times 1}{\mu} d t+\underset{n \times k}{\sum_{n \times 1}^{\prime}} d W(t), \\
& \frac{d B(t)}{B(t)}=r(t) d t,
\end{aligned}
$$

where $I_{S}$ is a diagonal matrix containing the asset prices (as in vector $S(t)$ ), $\mu$ is the vector of the expected returns on risky assets, and $\Sigma$ is the volatility matrix.

In a general equilibrium framework, the values $\mu, \Sigma$, and $r$ are endogenously determined. By Walras' law, however, we cannot determine these three prices $(\mu, \Sigma$, and $r)$ univocally. According to the standard approach (see, e.g., Cvitanić and Zapatero, 2004, Part III), therefore we determine: (i) the risk-free interest rate $r$, and (ii) the market price of risk $\xi$. Assuming the existence of the left inverse of matrix $\Sigma^{\prime}$, the market price of risk is therefore equal to

$$
\xi \equiv \Sigma^{\prime-1}(\mu-r \mathbf{1}),
$$

where 1 is a vector of $1^{\prime} \mathrm{s} .{ }^{11}$

Under the risk neutral probability measure $(\mathbb{Q})$ the expected return of any traded asset on the financial market must equate the risk-free interest rate. This means that the equality

$$
\underset{n \times n}{I_{S}^{-1}} \underset{n \times 1}{S(t)}=r \underset{n \times 1}{1} d t+\underset{n \times k}{\sum_{n \times 1}^{\prime}} d W_{k \times 1}^{\mathbb{Q}}(t) .
$$

must hold. Moreover, notice that (14) must coincide with (11). Therefore, equating the RHS of Equations (11) and (14) gives

$$
r \mathbf{1} d t+\Sigma^{\prime} d W^{\mathbb{Q}}(t)=\mu d t+\Sigma^{\prime} d W(t),
$$

or equivalently,

$$
d W^{\mathbb{Q}}(t)=\Sigma^{\prime-1}(\mu-r \mathbf{1}) d t+d W(t) .
$$

The stochastic process (15) shows that $\xi$, as defined in (13), allows to switch from the historical to the risk neutral probability measure (and vice versa).

\footnotetext{
${ }^{11}$ For further details see, e.g., Duffie and Zame (1989).
} 
In particular, it is possible to prove (see, e.g., Duffie, 1996, ch. 6) that the market price of risk and the kernel price $m\left(t_{0}, t\right)$ are linked by the following differential equation

$$
\begin{aligned}
\frac{d m\left(t_{0}, t\right)}{m\left(t_{0}, t\right)} & =-\xi^{\prime} d W(t) \\
m\left(t_{0}, t_{0}\right) & =1
\end{aligned}
$$

The public sector The government levies a tax rate $\tau$ on comprehensive income. The same tax rate $\tau$ is applied to:

1. risk-free asset return, and so the after-tax rate is

$$
r_{\tau}=(1-\tau) r
$$

2. risky asset returns, and so the after-tax returns are

$$
\mu_{\tau}=(1-\tau) \mu
$$

Given these results, we can write the after-tax market price of risk as follows:

$$
\begin{aligned}
\xi_{\tau} & =\Sigma^{\prime-1}\left(\mu_{\tau}-r_{\tau} \mathbf{1}\right) \\
& =(1-\tau) \Sigma^{\prime-1}(\mu-r \mathbf{1})=(1-\tau) \xi .
\end{aligned}
$$

The diffusion matrix $\Sigma$ is unaffected by taxation because the tax is not levied on the stock price but rather on the stock returns.

Let us next introduce the following:

Assumption 3 At any time, public spending is always equal to tax revenue, and has no direct impact on the private sector (i.e., on consumers and firms).

According to Assumption 3, taxation can be interpreted as simply being a real drain on the economy (Aseaa and Turnovsky, 1998). ${ }^{12}$ Assumption 3 has two main implications. Firstly, the public budget constraint is always in equilibrium and therefore, the government does not issue any public debt

\footnotetext{
${ }^{12}$ Assumption 3 is in line with most of the relevant literature (see, e.g., Rebelo, 1991, and Abel, 2007). An alternative way of focusing on distortionary effects is to assume that revenue is rebated to taxpayers in order to eliminate income effects (Gordon, 1985).
} 
bond. Secondly, public spending has no direct impact on the private sector, i.e., it affects neither the marginal utility of private consumption nor the firm productivity.

Given these assumptions, the after-tax cash flow, denoted as $\pi_{\tau}(t) \equiv$ $(1-\tau) \pi(t)+\tau \delta(t)$, evolves as follows:

$$
\begin{aligned}
d \pi_{\tau}(t) & =(1-\tau) d \pi(t)+\tau d \delta(t) \\
& =(1-\tau)\left(\mu_{\pi} d t+\sigma_{\pi}^{\prime} d W\right)+\tau d \delta(t) .
\end{aligned}
$$

Let us next find the depreciation rule that ensures neutrality in general equilibrium. A priori, we do not know whether this neutral depreciation allowance is deterministic or stochastic. ${ }^{13}$ Therefore, let us introduce a general depreciation allowance that evolves as follows:

$$
d \delta(t)=\mu_{\delta}(t, \delta) d t+\sigma_{\delta}(t, \delta)^{\prime} d W(t),
$$

where $\mu_{\delta}$ and $\sigma_{\delta}^{\prime}$ are the unknown drift and volatility parameters, respectively. We will therefore find the values of $\mu_{\delta}$ and $\sigma_{\delta}^{\prime}$ that ensure neutrality. Substituting (18) into (17) gives

$$
\begin{aligned}
d \pi_{\tau}(t) & =(1-\tau) d \pi(t)+\tau d \delta(t) \\
& =\left((1-\tau) \mu_{\pi}+\tau \mu_{\delta}\right) d t+\left((1-\tau) \sigma_{\pi}^{\prime}+\tau \sigma_{\delta}^{\prime}\right) d W
\end{aligned}
$$

The equilibrium To complete the model we need a market-clearing condition, according to which distributed dividends are fully consumed, i.e.,

$$
(1-\tau) \pi(t)+\tau \delta(t)=c(t) .
$$

Given the above assumptions, we can write the following:

Proposition 1 The equilibrium spot interest rate and market price of risk are equal to:

$$
\begin{aligned}
r= & \frac{\rho}{1-\tau}-\frac{1}{1-\tau} \frac{1}{d t} \mathbb{E}_{t}\left[\frac{d U^{\prime}((1-\tau) \pi(t)+\tau \delta(t))}{U^{\prime}((1-\tau) \pi(t)+\tau \delta(t))}\right] \\
= & \frac{\rho}{1-\tau}+A_{\tau} \frac{(1-\tau) \mu_{\pi}+\tau \mu_{\delta}}{1-\tau} \\
& +\frac{1}{2} K_{\tau} \frac{\left((1-\tau) \sigma_{\pi}^{\prime}+\tau \sigma_{\delta}^{\prime}\right)\left((1-\tau) \sigma_{\pi}+\tau \sigma_{\delta}\right)}{1-\tau}
\end{aligned}
$$

\footnotetext{
${ }^{13} \mathrm{By}$ assuming that the depreciation rule may be stochastic we let the government manage risk by means of tax revenue.
} 


$$
\xi^{\prime}=A_{\tau} \frac{(1-\tau) \sigma_{\pi}^{\prime}+\tau \sigma_{\delta}^{\prime}}{1-\tau}
$$

respectively, with

$$
\begin{gathered}
A_{\tau} \equiv-\frac{U^{\prime \prime}((1-\tau) \pi+\tau \delta)}{U^{\prime}((1-\tau) \pi+\tau \delta)} \\
K_{\tau} \equiv-\frac{U^{\prime \prime \prime}((1-\tau) \pi+\tau \delta)}{U^{\prime}((1-\tau) \pi+\tau \delta)}
\end{gathered}
$$

where $U^{\prime}(\cdot), U^{\prime \prime}(\cdot)$ and $U^{\prime \prime \prime}(\cdot)$ are the first, second and third derivative of $U(\cdot)$, respectively.

\section{Proof. See Appendix A}

In line with Duffie and Zame (1989), Proposition 1 shows that the spot interest rate is given by the subjective discount rate minus the expected rate of change in marginal utility (see the first line of Equation (21)). As can be seen in the second and third lines of (21), the spot interest rate $r$ depends on consumer's preferences (i.e., $\rho$ and the utility function) as well as on a firm's business activity (i.e., $\mu_{\pi}$ and $\sigma_{\pi}$ ). In particular, $r$ is given by three terms. The first term is equal to the intertemporal rate of substitution, divided by $(1-\tau)$. The second and third terms account for the Arrow-Pratt risk aversion measure $A_{\tau}$, and the third-order derivative of utility in $K_{\tau}$, respectively. We can see that risk (measured by $\sigma_{\pi}$ ) matters only if the third derivative of the utility function (in $K$ ) does not equal zero. This is due to the fact that $U^{\prime \prime \prime}((1-\tau) \pi+\tau \delta)$ allows us to measure the difference between the expected and the actual marginal utility. ${ }^{14}$

\footnotetext{
${ }^{14}$ To understand how the third derivative of the utility function $U(x)$ matters, let us assume a stochastic variable that evolves as follows:

$$
d x=\mu_{x} d t+\sigma_{x} d W .
$$
}

If we expand the utility function $U(x+d x)$ in Taylor series around $d x=0$ we have:

$$
U(x+d x) \simeq U(x)+U^{\prime}(x) d x+\frac{1}{2} U^{\prime \prime}(x)(d x)^{2}+\frac{1}{6} U^{\prime \prime \prime}(x)(d x)^{3} .
$$

Rearranging and taking expectations gives

$$
\mathbb{E}\left[\frac{U(x+d x)-U(x)}{d x}\right]-U^{\prime}(x) \simeq \frac{1}{2} U^{\prime \prime}(x) \mu_{x} d t+\frac{1}{6} U^{\prime \prime \prime}(x) \sigma_{x}^{2} d t .
$$

As can be seen, the term $U^{\prime \prime \prime}(x)$ matters only in a stochastic context (i.e., with $\sigma_{x}^{2} \neq 0$ ). 
As shown in Eq. (22), the equilibrium value of $\xi$ is given by the product between the Arrow-Pratt risk aversion measure and the term $\left(\sigma_{\pi}^{\prime}+\frac{\tau}{1-\tau} \sigma_{\delta}^{\prime}\right)$, that measures a firm's after-tax volatility. In other words, the equilibrium market price of risk is given by the product between cash flow risk and risk aversion. Accordingly, the higher the risk aversion and/or the risk itself, the higher the market price of risk is.

Given Proposition 1, we can now calculate the values of $\mu_{\delta}$ and $\sigma_{\delta}$ that ensure neutrality. We can thus prove the following:

Proposition 2 The depreciation rule ensuring tax invariance in general equilibrium is such that:

$$
\begin{gathered}
\mu_{\delta}=-\frac{\rho}{A_{\tau}}+\left(\frac{A}{A_{\tau}}-1\right) \frac{1-\tau}{\tau} \mu_{\pi} \\
+\frac{1}{2} \frac{K_{\tau}}{A_{\tau}}\left(\frac{K}{K_{\tau}}-\left(\frac{A}{A_{\tau}}\right)^{2}(1-\tau)\right) \frac{1-\tau}{\tau} \sigma_{\pi}^{\prime} \sigma_{\pi}, \\
\sigma_{\delta}^{\prime}=\left(\frac{A}{A_{\tau}}-1\right) \frac{1-\tau}{\tau} \sigma_{\pi}^{\prime},
\end{gathered}
$$

where $A_{\tau}$ and $K_{\tau}$ are as in (23) and (24), respectively, with $\left.A \equiv A_{\tau}\right|_{\tau=0}$, and $\left.K \equiv K_{\tau}\right|_{\tau=0}$.

Proof. See Appendix B.

Proposition 2 finds the depreciation rule (i.e., the values of $\mu_{\delta}$ and $\sigma_{\delta}$ ) that makes both the interest rate and the market price of risk tax invariant. As can be seen, this depreciation allowance is stochastic (i.e., $\sigma_{\delta}^{\prime} \neq \mathbf{0}$ ): this means that the government must actively manage risk in order to achieve neutrality.

If we compare, on the one hand (21) and (22), and on the other hand, (25) and (26), we can see a parallel between the optimal depreciation rule $\left(\mu_{\delta}, \sigma_{\delta}\right)$ and the optimal prices $(r, \xi)$. In particular, $\xi$ is proportional to the after-tax cash flow volatility, and $\sigma_{\delta}$ is proportional to the pre-tax cash flow volatility. Moreover, $r$ and $\mu_{\delta}$ are both proportional to the sum between the subjective discount rate $(\rho)$, the cash flow drift $\mu_{\pi}$, and the cash flow variance $\sigma_{\pi}^{\prime} \sigma_{\pi}$.

Let us next compare the JST rule of Equation (9) with the generalequilibrium one, given by (25)-(26). We can prove that: 
Proposition 3 The general equilibrium rule (25)-(26) coincides with the JST depreciation rule (9) if and only if

$$
\mu_{\pi}=\mu_{\delta}, \quad \sigma_{\pi}=\sigma_{\delta}
$$

These conditions hold if and only if the utility function is such that

$$
\begin{gathered}
A-\frac{A_{\tau}}{1-\tau}=0, \\
K-\frac{K_{\tau}}{1-\tau}=2 \frac{\tau}{1-\tau} \frac{\rho}{\sigma_{\pi}^{\prime} \sigma_{\pi}} .
\end{gathered}
$$

Proof. See Appendix C.

Proposition 3 shows that the neutrality rule (25)-(26) differs from the JST one, unless fairly restrictive conditions hold. As we can see, the rule determined by (25) and (26) crucially depends on the functional form of consumer's utility, while the JST depreciation rule (9) does not. In particular, Proposition 3 proves that the JST rule coincides with the general equilibrium rule (25)-(26) if and only if conditions (27) hold or (which is the same) if and only if conditions (27) hold. These two last conditions ask for the utility function to have an ad hoc functional form. However, we can prove that:

Corollary 1 Conditions (28) and (29) do not hold if the utility function belongs to the Hyperbolic Absolute Risk Aversion (HARA) family.

Proof. See Appendix D.

According to Corollary 1, therefore, (28) and (29) are not met when we use the most common forms of the utility function. In fact, Constant Relative Risk Aversion, Constant Absolute Risk Aversion, log, and quadratic utility functions can all be obtained as special cases of the more general HARA function. To sum up, we can say that, according to Proposition 3 and Corollary 1 , the JST rule cannot ensure neutrality in a realistic generalequilibrium setting.

On the other hand, we must say that the neutral depreciation rule of Proposition 2 is not a satisfactory solution, for two reasons. Firstly, the amount of tax revenue that can be raised from a firm by the general equilibrium tax rule (25)-(26) is nil. The reasoning behind this result is straightforward: conditions (27) require that the depreciation allowance must have the same drift and diffusion terms as the cash flow. This implies that $\pi$ and 
$\delta$ must coincide. In other words, the government must rebate everything it raises with taxation $(\tau \pi)$ to the firm $(\tau \delta)$. Consequently, a firm's effective tax burden is null. ${ }^{15}$ The second shortcoming of this neutrality rule is related to information requirements. As shown in Proposition 2, the neutral tax rule (25)-(26) crucially depends on volatility and is therefore risk-specific. This means that, if more than one firm operates, a firm-specific rule would be required to achieve neutrality, unless firms were all identical. Since this neutral rule is informationally very demanding, a dramatic implementation issue arises.

\section{Conclusion}

In this article, we have shown that the celebrated Johansson-Samuelson Theorem may fail to hold in general equilibrium, unless harsh and unrealistic assumptions are set. Moreover, we have discussed an alternative rule that ensures neutrality in general equilibrium. However, this rule has two shortcomings. Firstly, it implies that the effective tax burden on firms is nil and secondly, it suffers from implementation problems, in that it requires a huge amount of information. We can therefore conclude that a neutral uniform-tax system is harder to implement than usually thought.

\footnotetext{
${ }^{15}$ This zero-revenue result is similar to that obtained by Abel (2007) in a deterministic context. Contrary to Abel (2007), however, this result does not depend on the technology adopted.
} 


\section{A Proof of Proposition 1}

The Lagrangian function of Problem (10) is

$$
\begin{aligned}
\mathcal{L}= & \mathbb{E}_{t_{0}}\left[\int_{t_{0}}^{T} e^{-\rho\left(t-t_{0}\right)} U(c(t)) d t\right] \\
& -\lambda\left(\mathbb{E}_{t_{0}}\left[\int_{t_{0}}^{T} c(t) \frac{B\left(t_{0}\right)}{B(t)} m\left(t_{0}, t\right) d t\right]-R\left(t_{0}\right)\right) \\
= & \mathbb{E}_{t_{0}}\left[\int_{t_{0}}^{T}\left(e^{-\rho\left(t-t_{0}\right)} U(c(t))-\lambda c(t) \frac{B\left(t_{0}\right)}{B(t)} m\left(t_{0}, t\right)\right) d t\right]+\lambda R\left(t_{0}\right) .
\end{aligned}
$$

The first order condition on (30) is

$$
\mathbb{E}_{t_{0}}\left[\int_{t_{0}}^{T}\left(e^{-\rho\left(t-t_{0}\right)} U^{\prime}(c(t))-\lambda \frac{B\left(t_{0}\right)}{B(t)} m\left(t_{0}, t\right)\right) d t\right]=0
$$

where $U^{\prime}(\cdot)$ is the first derivative of function $U$. Since this first order condition must hold for any state of the world, then we can set the integrand function equal to zero (for any time $t$ ). Since the utility function is assumed to be strictly increasing and concave, then the marginal utility is invertible and so we can rearrange (31) as follows:

$$
c(t)=U^{\prime-1}\left(\lambda \frac{B\left(t_{0}\right)}{B(t)} m\left(t_{0}, t\right) e^{\rho\left(t-t_{0}\right)}\right) .
$$

Equation (20) implies that in equilibrium consumption must be equal to the after-tax dividend at any time. If we apply the marginal utility $U^{\prime}(\cdot)$ to both sides of the market-clearing Equation (20), we obtain

$$
U^{\prime}((1-\tau) \pi(t)+\tau \delta(t))=\lambda \frac{B\left(t_{0}\right)}{B(t)} m\left(t_{0}, t\right) e^{\rho\left(t-t_{0}\right)} .
$$

Applying Ito's Lemma to the RHS of (32), and using (12) and (16), we obtain

$$
\begin{aligned}
d\left(\lambda \frac{B\left(t_{0}\right)}{B(t)} m\left(t_{0}, t\right) e^{\rho\left(t-t_{0}\right)}\right)= & \lambda \frac{B\left(t_{0}\right)}{B(t)} m\left(t_{0}, t\right) e^{\rho\left(t-t_{0}\right)}(\rho-(1-\tau) r(t)) d t \\
& -\lambda \frac{B\left(t_{0}\right)}{B(t)} m\left(t_{0}, t\right) e^{\rho\left(t-t_{0}\right)}(1-\tau) \xi^{\prime} d W,
\end{aligned}
$$


which can be written as

$$
\frac{d U^{\prime}((1-\tau) \pi(t)+\tau \delta(t))}{U^{\prime}((1-\tau) \pi(t)+\tau \delta(t))}=(\rho-(1-\tau) r(t)) d t-(1-\tau) \xi^{\prime} d W .
$$

Taking the expected value of Equation (33) and solving for $r$, gives the first line of Equation (21). Furthermore, let us apply Ito's lemma to $U^{\prime}((1-\tau) \pi(t)+\tau \delta(t))$. Using Equation (19) we have:

$$
\begin{aligned}
& d U^{\prime}((1-\tau) \pi(t)+\tau \delta(t)) \\
= & U^{\prime \prime}((1-\tau) \pi(t)+\tau \delta(t))\left((1-\tau) \mu_{\pi}+\tau \mu_{\delta}\right) d t \\
& +\frac{1}{2} U^{\prime \prime \prime}((1-\tau) \pi(t)+\tau \delta(t))\left((1-\tau) \sigma_{\pi}^{\prime}+\tau \sigma_{\delta}^{\prime}\right)\left((1-\tau) \sigma_{\pi}+\tau \sigma_{\delta}\right) d t \\
& +U^{\prime \prime}((1-\tau) \pi(t)+\tau \delta(t))\left((1-\tau) \sigma_{\pi}^{\prime}+\tau \sigma_{\delta}^{\prime}\right) d W,
\end{aligned}
$$

where $U^{\prime \prime}(\cdot)$ and $U^{\prime \prime \prime}(\cdot)$ are the second and the third derivative of the utility function, respectively.

Notice that Equations (33) and (34) must be identical. Therefore, we can find the equilibrium prices by equating the drift and diffusion components of (33) and (34). Rearranging we obtain the equilibrium values for both $r$ and $\xi$, i.e.,

$$
\begin{aligned}
r(t)= & \frac{\rho}{1-\tau}-\frac{U^{\prime \prime}\left(\pi_{\tau}(t)\right)}{U^{\prime}\left(\pi_{\tau}(t)\right)} \frac{(1-\tau) \mu_{\pi}+\tau \mu_{\delta}}{1-\tau} \\
& -\frac{1}{2} \frac{U^{\prime \prime \prime}\left(\pi_{\tau}(t)\right)}{U^{\prime}\left(\pi_{\tau}(t)\right)} \frac{\left((1-\tau) \sigma_{\pi}^{\prime}+\tau \sigma_{\delta}^{\prime}\right)\left((1-\tau) \sigma_{\pi}+\tau \sigma_{\delta}\right)}{1-\tau},
\end{aligned}
$$

and

$$
\xi^{\prime}=-\frac{U^{\prime \prime}\left(\pi_{\tau}(t)\right)}{U^{\prime}\left(\pi_{\tau}(t)\right)} \frac{(1-\tau) \sigma_{\pi}^{\prime}+\tau \sigma_{\delta}^{\prime}}{1-\tau} .
$$

Using (35) and (36) one easily obtains (21) and (22). Proposition 1 is thus proven.

\section{B Proof of Proposition 2}

Let us calculate the values of $\mu_{\delta}$ and $\sigma_{\delta}$ that ensure tax invariance of market prices. Firstly, in order for $\xi$ to be unaffected by taxation, its value in (36) must be equal to the same value obtained with $\tau=0$, i.e., we must have

$$
-\frac{U^{\prime \prime}\left(\pi_{\tau}(t)\right)}{U^{\prime}\left(\pi_{\tau}(t)\right)} \frac{(1-\tau) \sigma_{\pi}^{\prime}+\tau \sigma_{\delta}^{\prime}}{1-\tau}=-\frac{U^{\prime \prime}(\pi(t))}{U^{\prime}(\pi(t))} \sigma_{\pi}^{\prime},
$$


which gives

$$
\sigma_{\delta}^{\prime}=\left(\frac{U^{\prime}\left(\pi_{\tau}(t)\right)}{U^{\prime \prime}\left(\pi_{\tau}(t)\right)} \frac{U^{\prime \prime}(\pi(t))}{U^{\prime}(\pi(t))}-1\right) \frac{1-\tau}{\tau} \sigma_{\pi}^{\prime} .
$$

Using function (23) and setting $\left.A \equiv A_{\tau}\right|_{\tau=0}$, we can rewrite (37) as (26).

Let us next focus on the interest rate. In order for the equality $r_{\tau}(t)=$ $r(t)$ to hold, we must set the equilibrium value of the spot interest rate in (35) equal to that obtained with $\tau=0$. Therefore, we must have:

$$
\begin{aligned}
& \frac{\rho}{1-\tau}-\frac{U^{\prime \prime}\left(\pi_{\tau}(t)\right)}{U^{\prime}\left(\pi_{\tau}(t)\right)} \frac{(1-\tau) \mu_{\pi}+\tau \mu_{\delta}}{1-\tau} \\
- & -\frac{1}{2} \frac{U^{\prime \prime \prime}\left(\pi_{\tau}(t)\right)}{U^{\prime}\left(\pi_{\tau}(t)\right)} \frac{\left((1-\tau) \sigma_{\pi}^{\prime}+\tau \sigma_{\delta}^{\prime}\right)\left((1-\tau) \sigma_{\pi}+\tau \sigma_{\delta}\right)}{1-\tau} \\
= & \rho-\frac{U^{\prime \prime}(\pi(t))}{U^{\prime}(\pi(t))} \mu_{\pi}-\frac{1}{2} \frac{U^{\prime \prime \prime}(\pi(t))}{U^{\prime}(\pi(t))} \sigma_{\pi}^{\prime} \sigma_{\pi} .
\end{aligned}
$$

Rearranging and solving (38) with respect to $\mu_{\delta}$ gives $^{16}$

$$
\begin{aligned}
\mu_{\delta}= & \frac{U^{\prime}\left(\pi_{\tau}(t)\right)}{U^{\prime \prime}\left(\pi_{\tau}(t)\right)} \rho \\
& +\left(\frac{U^{\prime}\left(\pi_{\tau}(t)\right)}{U^{\prime \prime}\left(\pi_{\tau}(t)\right)} \frac{U^{\prime \prime}(\pi(t))}{U^{\prime}(\pi(t))}-1\right) \frac{1-\tau}{\tau} \mu_{\pi} \\
& +\frac{1}{2} \frac{U^{\prime}\left(\pi_{\tau}(t)\right)}{U^{\prime \prime}\left(\pi_{\tau}(t)\right)} \frac{U^{\prime \prime \prime}(\pi(t))}{U^{\prime}(\pi(t))} \frac{1-\tau}{\tau} \sigma_{\pi}^{\prime} \sigma_{\pi} \\
& -\frac{1}{2} \frac{U^{\prime}\left(\pi_{\tau}(t)\right)}{U^{\prime \prime}\left(\pi_{\tau}(t)\right)} \frac{U^{\prime \prime \prime}\left(\pi_{\tau}(t)\right)}{U^{\prime}\left(\pi_{\tau}(t)\right)}\left(\frac{U^{\prime}\left(\pi_{\tau}(t)\right)}{U^{\prime \prime}\left(\pi_{\tau}(t)\right)} \frac{U^{\prime \prime}(\pi(t))}{U^{\prime}(\pi(t))}\right)^{2} \frac{(1-\tau)^{2}}{\tau} \sigma_{\pi}^{\prime} \sigma_{\pi} .
\end{aligned}
$$

Using the function (24), setting $\left.K \equiv K_{\tau}\right|_{\tau=0}$, and rearranging (39) gives (25). We have therefore obtained a tax policy $\left(\mu_{\delta}, \sigma_{\delta}\right)$ that ensures the tax invariance of equilibrium market prices. Proposition 2 is thus proven.

\section{Proof of Proposition 3}

As proven in Proposition 2, the depreciation rule (25)-(26) ensures the following equalities:

$$
\begin{aligned}
r_{\tau}(t) & =r(t), \\
\xi_{\tau}^{\prime} & =\xi^{\prime} .
\end{aligned}
$$

\footnotetext{
${ }^{16}$ We have already substituted the tax invariance value of $\sigma_{\delta}$ previously obtained.
} 
Since the risk-free interest rate $r(t)$ is the same before and after taxation, then we have:

$$
\begin{aligned}
& \mu_{r, \tau}=\mu_{r}, \\
& \sigma_{r, \tau}=\sigma_{r} .
\end{aligned}
$$

Since the after-tax cash flow $\pi_{\tau}$ evolves according to

$$
d \pi_{\tau}=\left((1-\tau) \mu_{\pi}+\tau \mu_{\delta}\right) d t+\left((1-\tau) \sigma_{\pi}^{\prime}+\tau \sigma_{\delta}^{\prime}\right) d W,
$$

we can therefore write its drift and diffusion terms as:

$$
\begin{aligned}
& \mu_{\pi, \tau}=(1-\tau) \mu_{\pi}+\tau \mu_{\delta} \\
& \sigma_{\pi, \tau}^{\prime}=(1-\tau) \sigma_{\pi}^{\prime}+\tau \sigma_{\delta}^{\prime} .
\end{aligned}
$$

Substituting $\mu_{r, \tau}, \sigma_{r, \tau}, \mu_{\pi, \tau}$ and $\sigma_{\pi, \tau}$ into the JST depreciation rule (8) we obtain

$$
\begin{aligned}
\delta(t)= & r(t) V(t)-\pi(t)+\frac{\partial V(t)}{\partial \pi(t)}\left(\mu_{\pi}-\mu_{\delta}\right) \\
& +\frac{\partial^{2} V(t)}{\partial r(t) \partial \pi(t)}\left(\sigma_{\pi}^{\prime}-\sigma_{\delta}^{\prime}\right) \sigma_{r}+\frac{1}{2} \frac{\partial^{2} V(t)}{\partial \pi(t)^{2}}\left(2 \sigma_{\pi}^{\prime}-\tau\left(\sigma_{\pi}^{\prime}-\sigma_{\delta}^{\prime}\right)\right)\left(\sigma_{\pi}-\sigma_{\delta}\right) .
\end{aligned}
$$

Equation (40) coincides with the JST rule (9) if and only if

$$
\begin{aligned}
\mu_{\pi} & =\mu_{\delta}, \\
\sigma_{\pi} & =\sigma_{\delta} .
\end{aligned}
$$

In particular, (40) is equal to (9) for any value of $\pi(t)$ and $r(t)$, if and only if the coefficients of all the derivatives of $V(t)$ are set equal to zero. These coefficients are zero if and only if $\mu_{\pi}=\mu_{\delta}$ and $\sigma_{\pi}=\sigma_{\delta}$.

Let us finally find conditions (28) and (29). From Equation (26), we can see that $\sigma_{\pi}=\sigma_{\delta}$ if and only if the utility function is such that condition

$$
A-\frac{A_{\tau}}{1-\tau}=0
$$

holds, where $A_{\tau}$ is as in (23) and $\left.A \equiv A_{\tau}\right|_{\tau=0}$. Substituting this condition into Equation (25) we can see that $\mu_{\pi}=\mu_{\delta}$ if and only if the utility function is such that

$$
K-\frac{K_{\tau}}{1-\tau}=2 \frac{\tau}{1-\tau} \frac{\rho}{\sigma_{\pi}^{\prime} \sigma_{\pi}},
$$

where $K_{\tau}$ is as in (24) and $\left.K \equiv K_{\tau}\right|_{\tau=0}$. This concludes the proof of Proposition 3. 


\section{Proof of Corollary 1}

To prove Corollary 1, let us assume that a consumer's utility function is equal to

$$
U(c)=\frac{(\alpha+\gamma c)^{1-\frac{\beta}{\gamma}}-1}{\gamma-\beta},
$$

where $\beta>0, c>-\frac{\alpha}{\gamma}$, while $\alpha$ and $\gamma$ are parameters. Function (41) belongs to the so-called Hyperbolic Absolute Risk Aversion (HARA) family. It can be traced back to the usual utility functions studied in the relevant literature by using the following parameter combinations:

1. with $\alpha=0, \gamma=1$, we obtain a power utility function (Constant Relative Risk Aversion):

$$
U(c)=\frac{c^{1-\beta}-1}{1-\beta},
$$

2. with $\alpha=1$, and $\gamma$ tending towards 0 , we obtain an exponential utility function (Constant Absolute Risk Aversion):

$$
U(c)=\frac{1-e^{-\beta c}}{\beta},
$$

3. with $\alpha=0, \gamma=1$, and $\beta=1$, we obtain the log utility function:

$$
U(c)=\ln c,
$$

4. with $\gamma=-\beta$ we obtain the quadratic utility function:

$$
U(c)=\frac{(\alpha-\beta c)^{2}-1}{-2 \beta} .
$$

Let us next calculate the first, second, and third derivatives of (41):

$$
\begin{aligned}
U^{\prime}(c) & =(\alpha+\gamma c)^{-\frac{\beta}{\gamma}} \\
U^{\prime \prime}(c) & =-\beta(\alpha+\gamma c)^{-\frac{\beta}{\gamma}-1} \\
U^{\prime \prime \prime}(c) & =\beta(\beta+\gamma)(\alpha+\gamma c)^{-\frac{\beta}{\gamma}-2}
\end{aligned}
$$


In this case, condition (28) holds if and only if

$$
\frac{\beta}{\alpha+\gamma c}-\frac{1}{1-\tau} \frac{\beta}{\alpha+\gamma((1-\tau) c+\tau \delta)}=0
$$

which can be written as

$$
\left(\gamma(1-\tau)^{2}-\gamma\right) c-\tau \alpha+\gamma(1-\tau) \tau \delta=0 .
$$

Polynomial (42) is zero for any value of $c$ if and only if all the coefficients of $c$ are zero, i.e.,

$$
\left\{\begin{array}{l}
\gamma(1-\tau)^{2}-\gamma=0 \\
-\tau \alpha+\gamma(1-\tau) \tau \delta=0
\end{array}\right.
$$

As we can see, the only solution (with $\tau \neq 0$ ) is

$$
\gamma=0, \quad \alpha=0
$$

However, the parameter $\gamma$ can be zero only if $\alpha=1$. This means that condition (28) does not hold for any utility function generally used in the literature. 


\section{References}

[1] Abel A.B. (2007), Optimal Capital Income Taxation, NBER W.P. 13354.

[2] Aseaa P.K. and S.J. Turnovsky (1998), Capital Income Taxation and Risk-Taking in a Small Open Economy, Journal of Public Economics, 68, pp. 55-90.

[3] Berk J.B., R.C. Green and V. Naik (1999), Optimal Investment, Growth Options, and Security Returns, The Journal of Finance, 54, pp. 15531607.

[4] Björk T. (1998), Arbitrage Theory in Continuous Time, Oxford University Press, Oxford.

[5] Boadway R. and N. Bruce (1984), A General Proposition on the Design of a Neutral Business Tax, Journal of Public Economics, 24, pp. 231-239.

[6] Bulow J.I. and L.H. Summers (1984), The Taxation of Risky Assets, Journal of Political Economy, 92, pp. 20-39.

[7] Cvitanić J. and F. Zapatero (2004), Economics and Mathematics of Financial Markets, MIT Press, Cambridge, Mass.

[8] Devereux M.P. (2003), Measuring Taxes on Income from Capital, in P.B. Sørensen (ed.), Measuring the Tax Burden on Capital and Labor, CESifo Seminar Series, MIT Press, Cambridge, Mass.

[9] Domar E.D. and R.A. Musgrave (1944), Proportional Income Taxation and Risk-taking, Quarterly Journal of Economics, 58, pp. 388-422.

[10] Duffie D. (1996), Dynamic Asset Pricing Theory, Princeton University Press, Princeton.

[11] Duffie D. and W. Zame (1989), The Consumption-Based Capital Asset Pricing Model, Econometrica, 57, pp. 1279-1297.

[12] Fane G. (1987), Neutral Taxation under Uncertainty, Journal of Public Economics, 33, pp. 95-105.

[13] Gomes J., L. Kogan and L. Zhang (2003), Equilibrium Cross Section of Returns, Journal of Political Economy, 111, pp. 693-732. 
[14] Gordon R.H. (1985), Taxation of Corporate Capital Income: Tax Revenues Versus Tax Distortions, Quarterly Journal of Economics, 100, pp. $1-27$.

[15] Hall R.E. and D.W. Jorgenson (1971), Application of the Theory of Optimal Capital Accumulation, in G. Fromm (ed.), Tax Incentives and Capital Spending, Studies of Government Finance, The Brooking Institutions, Washington D.C.

[16] Hartwick J.M., L. Karp and N. Van Long (2002), Depreciation Rules and Value Invariance with Extractive Firms, Journal of Economic Dynamics and Control, 26, pp. 99-116.

[17] Johansson S.-E. (1961), Skatt-Investering-Värdering, Stockholm.

[18] Johansson S.-E. (1969), Income Taxes and Investment Decisions, Swedish Journal of Economics, 71, pp. 104-110.

[19] Kaplow L. (1994), Taxation and Risk Taking: A General Equilibrium Perspective, National Tax Journal, 47, pp. 789-798.

[20] Lyon A.B. (1990), Invariant Valuation When Taxes Change Over Time, Journal of Political Economy, 98, pp. 433-437.

[21] Merton R.C. (1990), Continuous-Time Finance, Blackwell, Cambridge, Mass. and Oxford.

[22] Niemann R. (1999), Neutral Taxation under Uncertainty - A Real Option Approach, Finanzarchiv, 56, pp. 51-66.

[23] Niemann R. (2004), Tax Rate Uncertainty, Investment Decisions, and Tax Neutrality, International Tax and Public Finance, 11, pp. 265-281.

[24] Panteghini P.M. (2007), Corporate Taxation in a Dynamic World, Springer.

[25] President's Advisory Panel on Tax Reform (2005), Simple, Fair, and Pro-Growth: Proposals to Fix America's Tax System, Washington D.C.

[26] Rebelo S., 1991. Long-Run Policy Analysis and Long-Run Growth, Journal of Political Economy, 99, pp. 500-521. 
[27] Richter W.F. (1988), Comprehensive versus Neutral Income Taxation, in Bös D., M. Rose, and C. Seidl (editors), Welfare and Efficiency in Public Economics, pp. 281-295, Springer, New York, Berlin and Tokyo.

[28] Samuelson P.A. (1964), Tax Deductibility of Economic Depreciation to Insure Invariant Valuations, Journal of Political Economy, 72, pp. 604606.

[29] Sinn H.W. (1987), Capital Income Taxation and Resource Allocation, North-Holland, Amsterdam and Tokyo.

[30] Vasicek O.A. (2005), The Economics of Interest Rates, Journal of Financial Economics, 76, pp. 293-307. 


\section{CESifo Working Paper Series}

for full list see www.cesifo-group.org/wp

(address: Poschingerstr. 5, 81679 Munich, Germany, office@cesifo.de)

2289 Mikael Priks, Do Surveillance Cameras Affect Unruly Behavior? A Close Look at Grandstands, April 2008

2290 Marianna Belloc and Daniela Federici, A Two-Country NATREX Model for the Euro/Dollar, April 2008

2291 Nicolas Treich, The Value of a Statistical Life under Ambiguity Aversion, April 2008

2292 J. Atsu Amegashie, Socially-Tolerable Discrimination, April 2008

2293 M. Hashem Pesaran and Andreas Pick, Forecasting Random Walks Under Drift Instability, April 2008

2294 Steven Brakman, Gus Garita, Harry Garretsen and Charles van Marrewijk, Unlocking the Value of Cross-Border Mergers and Acquisitions, May 2008

2295 Eric O’N. Fisher and Kathryn G. Marshall, The Structure of the American Economy, May 2008

2296 Claudia M. Buch and Martin Schlotter, Regional Origins of Employment Volatility: Evidence from German States, May 2008

2297 Helmuth Cremer, Philippe De Donder, Dario Maldonado and Pierre Pestieau, Taxing Sin Goods and Subsidizing Health Care, May 2008

2298 Reinhilde Veugelers and Frederick van der Ploeg, Reforming European Universities: Scope for an Evidence-Based Process, May 2008

2299 Jon H. Fiva and Lars J. Kirkebøen, Does the Housing Market React to New Information on School Quality?, May 2008

2300 Tina Klautke and Alfons J. Weichenrieder, Interest Income Tax Evasion, the EU Savings Directive, and Capital Market Effects, May 2008

2301 Harald Badinger and Peter Egger, GM Estimation of Higher Order Spatial Autoregressive Processes in Panel Data Error Component Models, May 2008

2302 Jan K. Brueckner, Slot-Based Approaches to Airport Congestion Management, May 2008

2303 Sören Blomquist, Vidar Christiansen and Luca Micheletto, Public Provision of Private Goods and Nondistortionary Marginal Tax Rates, May 2008

2304 Dan Anderberg and Alessandro Balestrino, The Political Economy of Post-Compulsory Education Policy with Endogenous Credit Constraints, May 2008 
2305 Tomer Blumkin, Yoram Margalioth and Efraim Sadka, The Role of Stigma in the Design of Welfare Programs, May 2008

2306 Vesa Kanniainen and Paolo M. Panteghini, Tax Neutrality: Illusion or Reality? The Case of Entrepreneurship, May 2008

2307 Thomas Dohmen, Armin Falk, David Huffman and Uwe Sunde, The Intergenerational Transmission of Risk and Trust Attitudes, May 2008

2308 Guglielmo Maria Caporale and Mario Cerrato, Using Chebyshev Polynomials to Approximate Partial Differential Equations, May 2008

2309 Peter Egger and Doina Maria Radulescu, Labour Taxation and Foreign Direct Investment, May 2008

2310 Laurent Linnemer, Dissipative Advertising Signals Quality even without Repeat Purchases, May 2008

2311 Jordi Jofre-Monseny and Albert Solé-Ollé, Which Communities should be afraid of Mobility? The Effects of Agglomeration Economies on the Sensitivity of Firm Location to Local Taxes, May 2008

2312 Andreas Haufler and Ferdinand Mittermaier, Unionisation Triggers Tax Incentives to Attract Foreign Direct Investment, May 2008

2313 Ronel Elul and Piero Gottardi, Bankruptcy: Is it enough to Forgive or must we also Forget?, May 2008

2314 Andreas Irmen and Johanna Kuehnel, Productive Government Expenditure and Economic Growth, May 2008

2315 Beate Henschel, Carsten Pohl and Marcel Thum, Demographic Change and Regional Labour Markets: The Case of Eastern Germany, May 2008

2316 Gabriel Felbermayr, Wido Geis and Wilhelm Kohler, Restrictive Immigration Policy in Germany: Pains and Gains Foregone?, May 2008

2317 Michael Hofmann, Gerhard Kempkes and Helmut Seitz, Demographic Change and Public Sector Budgets in a Federal System, May 2008

2318 Paul De Grauwe, Macroeconomic Modeling when Agents are Imperfectly Informed, June 2008

2319 Johann K. Brunner and Susanne Pech, Optimum Taxation of Inheritances, June 2008

2320 Thomas Eichner and Marco Runkel, Corporate Income Taxation of Multinationals in a General Equilibrium Model, June 2008

2321 Rainald Borck and Matthias Wrede, Subsidies for Intracity and Intercity Commuting, June 2008 
2322 Patricia Apps and Ray Rees, Testing the Pareto Efficiency of Household Resource Allocations, June 2008

2323 Amihai Glazer, Vesa Kanniainen and Panu Poutvaara, Firms' Ethics, Consumer Boycotts, and Signalling, June 2008

2324 Claudia M. Buch, Jörg Döpke and Kerstin Stahn, Great Moderation at the Firm Level? Unconditional vs. Conditional Output Volatility, June 2008

2325 Helmuth Cremer, Philippe De Donder, Dario Maldonado and Pierre Pestieau, Forced Saving, Redistribution and Nonlinear Social Security Schemes, June 2008

2326 M. Hashem Pesaran and Paolo Zaffaroni, Optimal Asset Allocation with Factor Models for Large Portfolios, June 2008

2327 Harald Badinger and Peter Egger, Horizontal versus Vertical Interdependence in Multinational Activity, June 2008

2328 Jan K. Brueckner and Harris Selod, A Theory of Urban Squatting and Land-Tenure Formalization in Developing Countries, June 2008

2329 Paolo M. Panteghini, Corporate Debt, Hybrid Securities and the Effective Tax Rate, June 2008

2330 Guglielmo Maria Caporale, Juncal Cuñado and Luis A. Gil-Alana, Modelling Long-Run Trends and Cycles in Financial Time Series Data, June 2008

2331 Avi Ben-Bassat and Momi Dahan, Social Identity and Voter Turnout, June 2008

2332 Martin R. West and Ludger Wößmann, "Every Catholic Child in a Catholic School”: Historical Resistance to State Schooling, Contemporary Private Competition, and Student Achievement across Countries, June 2008

2333 Erkki Koskela and Panu Poutvaara, Outsourcing and Labor Taxation in Dual Labor Markets, June 2008

2334 Philippe Choné and Laurent Linnemer, Optimal Litigation Strategies with Signaling and Screening, June 2008

2335 Albert Solé-Ollé and Pilar Sorribas-Navarro, Does Partisan Alignment Affect the Electoral Reward of Intergovernmental Transfers?, June 2008

2336 Antonio Cabrales and Piero Gottardi, Markets for Information: Of Inefficient Firewalls and Efficient Monopolies, June 2008

2337 Sumon Majumdar and Sharun W. Mukand, The Leader as Catalyst - on Leadership and the Mechanics of Institutional Change, June 2008

2338 Ulrich Hange, Tax Competition, Elastic Labor Supply, and Growth, June 2008 
2339 Guy Laroque and Bernard Salanié, Does Fertility Respond to Financial Incentives?, June 2008

2340 Adriano Paggiaro, Enrico Rettore and Ugo Trivellato, The Effect of Extending the Duration of Eligibility in an Italian Labour Market Programme for Dismissed Workers, June 2008

2341 Helmut Seitz, Minimum Standards, Fixed Costs and Taxing Autonomy of Subnational Governments, June 2008

2342 Robert S. Chirinko, Leo de Haan and Elmer Sterken, Asset Price Shocks, Real Expenditures, and Financial Structure: A Multi-Country Analysis, July 2008

2343 Wolfgang Leininger, Evolutionarily Stable Preferences in Contests, July 2008

2344 Hartmut Egger and Udo Kreickemeier, Fairness, Trade, and Inequality, July 2008

2345 Ngo Van Long and Bodhisattva Sengupta, Yardstick Competition, Corruption, and Electoral Incentives, July 2008

2346 Florian Baumann, Employment Protection: The Case of Limited Enforceability, July 2008

2347 Alessandro Balestrino, Cinzia Ciardi and Claudio Mammini, On the Causes and Consequences of Divorce, July 2008

2348 Dirk Schindler and Benjamin Weigert, Insuring Educational Risk: Opportunities versus Income, July 2008

2349 Lammertjan Dam and Ben J. Heijdra, The Environmental and Macroeconomic Effects of Socially Responsible Investment, July 2008

2350 Avner Greif, Contract Enforcement and Institutions among the Maghribi Traders: Refuting Edwards and Ogilvie, July 2008

2351 Helmuth Cremer, Philippe De Donder, Dario Maldonado and Pierre Pestieau, Habit Formation and Labor Supply, July 2008

2352 Francesco Menoncin and Paolo M. Panteghini, The Johansson-Samuelson Theorem in General Equilibrium: A Rebuttal, July 2008 